\title{
Experimental Investigation of Natural convective flow in Aluminium Open Cell heat exchanger
}

\author{
Rahul Singh Poonia ${ }^{+*}$ and Mandar M. Lele ${ }^{\ddagger}$ \\ †Maharashtra Institute of Technology, Pune, India \\ ‡Dept. of mechanical Engg, MIT College of engineering, Pune, India \\ Accepted 03 March 2016, Available online 15 March 2016, Special Issue-4 (March 2016)
}

\begin{abstract}
Aluminum Open cell heat exchanger with cell diameter $10 \mathrm{~mm}$ were manufactured having base area measuring $100 \mathrm{~mm} \times 45 \mathrm{~mm}$.It is attached to the copper Plate which is heated by a cylindrical heater inserted in copper plate. Other sides of Copper base plate are insulated so that heat flow is unidirectional and pass through the cellular structure. Results of Natural Convective heat transfer in Aluminum open cell heat exchanger heated from below are presented. Samples of Regular Aluminum Open cell cellular structure with porosity $(\epsilon=.55)$ having different height are used to study the effects of Geometry on heat transfer to air. Results indicate that with Aluminum open cell cellular structure attached to the copper plate the temperature of base copper plate has been considerably reduced for different heat flux in comparison with the base case when there is only copper plate heat from below with different heat flux. So the open cell cellular structure can dissipate higher amount heat for the same temperature difference and area of base plate (copper plate).
\end{abstract}

Keywords: Open cell cellular structure, Natural Convection, Porosity.

\section{Introduction}

Regular Aluminum open cell cellular structure is new kind of material popped up recently for use in thermal application since they are easy to manufacture. The cellular structure used in this study is in house manufactured. In the natural convective, the open cell cellular structure has numerous applications due to its high surface to volume ratio. Small ligaments create the lot of tortuous path and it has comparatively low weight.

\subsection{Natural convection in porous media}

Most of the Theoretical and numerical studies on natural convection in porous media are based on empirical models using Darcy formulation. The experimental study is limited to relatively few in number and deal with packed bed of spherical beads. They show significant discrepancies between numerical and experimental results Bhattacharya and Mahajan et al. (2006) have investigated influences of pore density and porosity for substrate temperatures up to $75^{\circ} \mathrm{C}$ for $\mathrm{Al}$-foams. They found that the heat transfer rate increases with decreasing porosity.

*Corresponding author: Rahul Singh Poonia
When the porosity is kept constant, the heat transfer rate increases for decreasing PPI-values. For copper foamed heat sinks, Qu et al. (2012) studied the influence of the inclination angle and the foam height. They have shown that the influence of the inclination angle for their cubic shaped heat sinks is not significant $(6 \%)$.

In free convection, many parameters affect the heat transfer rate in foams. Therefore, the foam material \& height, geometrical characteristics (PPI and porosity alone are not enough to describe a 3D material), substrate dimension, heat sink orientation, temperature of the substrate (or applied heat flux), bonding method, test constraints (thickness of the thermal paste, configuration of guard heaters etc.) and the box geometry should be reported. The objective of this study is to analyse whether the regular aluminium open cell cellular material can be used to dissipate more amount of heat for the same base area. The height of the samples is varied between 30 and 100 $\mathrm{mm}$.

\section{2 .Experimental set up and samples}

The experimental set as shown in the fig1. The dimensions of base plate measures $98 \times 30 \times 36 \mathrm{~mm}^{3}$ and is kept constant for all samples.The top surface of the plate is 
Placed level with the insulation. On top of this plate the regular Aluminum open cell cellular structure is placed The cylindrical heater is inserted in the copper plate. It is done by drilling a hole of $14.5 \mathrm{~mm}$. The hole is drilled in such a way that the gap between cylindrical heater and hole should not exceed $.2 \mathrm{~mm}$ for the satisfactory working of heater. Three holes are drilled in the copper plate for measuring the temperature of the copper plate the copper plate is insulated from all the sides by Glass fiber except where open cell cellular structure was kept. So that the heat conduction through the copper is unidirectional in nature. The best insulation has almost zero thermal conductivity and it is also able to withstand the higher temperature. So the material which is used for the experimentation is glass fiber. It has no true melting point but softens up to $1200^{\circ} \mathrm{C}$. A wooden box of $20 \mathrm{~mm}$ thickness is further used to enhance the insulation. The Temperature is recorded by Probe type thermocouple.

The Regular Aluminum open cell cellular structure measures $100 \times 100 \times 100 \mathrm{~mm}^{3}$ is manufactured in workshop as shown in fig3.

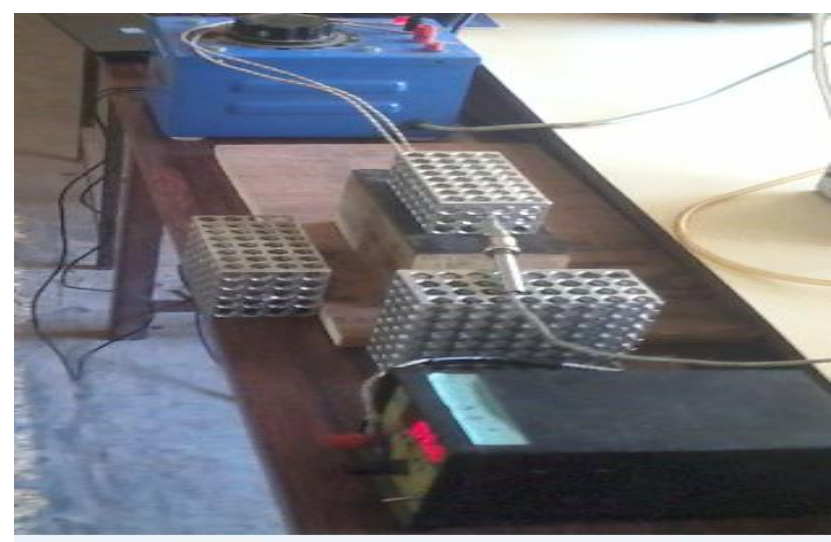

Fig 1: the experimental set up

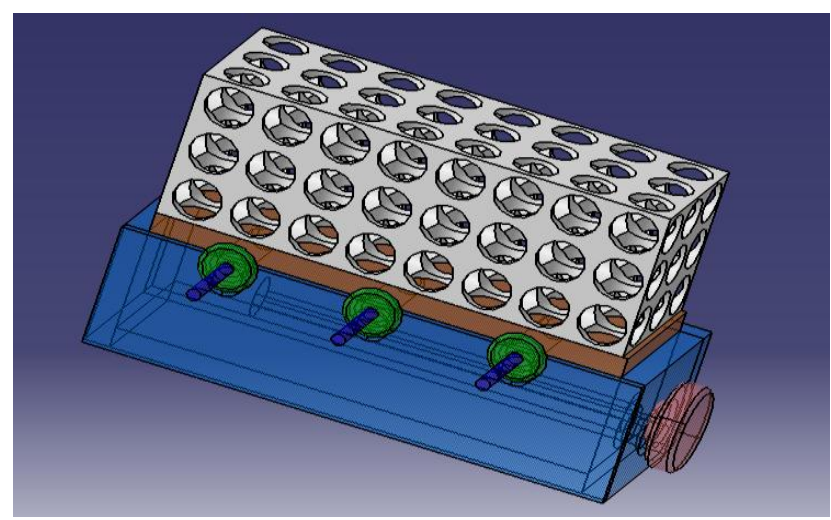

Fig 2: Cad model of experimental set up

A block of aluminum measuring $120 \times 120 \times 120 \mathrm{~mm}^{3}$ is taken and milled to the dimensions $100 \times 100 \times 100$ $\mathrm{mm}^{3}$. 192 holes are drilled in three perpendicular planes so that the resulting structure is open cell cellular structure. The resulting piece is cut into three sample pieces by using wire cutting machine as shown in fig2. Since, the particular material used don't have high porosity so it is not a highly porous metallic foam. The three sample piece have same porosity $(\epsilon=.55)$ but different height. ( $L_{1}=40 \mathrm{~mm}, L_{2}=60 \mathrm{~mm}, L_{3}=$ $100 \mathrm{~mm})$.

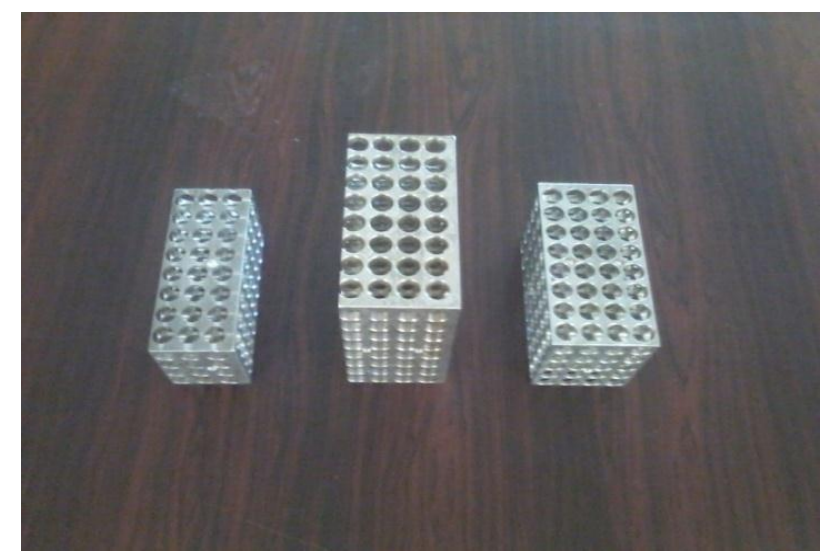

Fig 3. The sample pieces

During the experimental run the dimmer stat is used to control the heat produced (heat flux). The temperature of the base plate (copper plate) and temperature of different sides of cellular material are recorded for different heat flux. the range of heat flux were kept between $\left(1.9\right.$ to $\left.2.5 \mathrm{w} / \mathrm{cm}^{2}\right)$ the heat transfer coefficient for typical run was calculated based on the following equation.

$h=\frac{Q}{A\left(T_{\text {base }}-T_{a m b}\right)}$

\section{Data Reduction}

The energy $P$ generated in the open cell cellular material is dissipated by three mechanisms

$p=p_{\text {conv }}+p_{\text {cond }}+p_{\text {rad }}$

Where $\mathrm{p}$ is the heat produced and $p_{\text {conv }}, p_{\text {cond }}, p_{\text {rad }}$ are the heat losses by conduction, convection and radiation. For the steady state all the heat is finally convected and radiated so $p_{\text {cond }}$ can be neglected.

The heat transfer due to radiation is calculated from all the sides.

$$
\begin{gathered}
p_{\text {rad }}=2 \sigma A_{1} \epsilon_{a}\left(T_{b 1}^{4}-T_{a}^{4}\right)+2 \sigma A_{2} \epsilon_{a}\left(T_{b 2}^{4}-T_{a}^{4}\right)+ \\
\sigma A_{3} \epsilon_{a}\left(T_{b 3}^{4}-T_{a}^{4}\right)
\end{gathered}
$$

Where $\sigma$ the Stefan blotzmann is constant $\epsilon_{a}$ is the emissivity of the aluminum specimen and $T a$ is the ambient temperature. $T_{b 1}, T_{b 2}, T_{b 3}$ are the average temperature of cellular structure. The heat loss by natural convection is given by

$p_{\text {conv }}=p-p_{\text {rad }}$

Where $p_{\text {conv }}$ is the heat convected. 
Whereas the heat transfer through natural convection is also equal to

$P_{\text {conv }}=h_{\text {conv }} A\left(T_{\text {wall }}-T_{a}\right)$

\section{Readings}

Temperatures of copper plate have been measured for different heat flux with and without regular aluminum open cell cellular structure material attached to it.
The following reading has been taken for different heat flux the table1 show the reading of temperature of copper plate for different heat flux without open cell cellular structure attached to the copper plate. Table 2 shows the reading of copper plate and open cell cellular structure for different heat fluxes when open cell cellular structure is attached to the copper plate. $T_{1}, T_{2}, T_{3}$ are the readings of copper plate taken at different points and other $T_{4}, T_{5}, T_{6}, T_{7}, T_{8}, T_{9}$ are the temperature reading of different surfaces of open cell cellular structure.

Table1 temperature of the copper plate without aluminum open cell cellular structure

\begin{tabular}{|c|c|c|c|}
\hline Heat Generated (Watt) & $\mathrm{T}_{1}($ Deg C) & $\mathrm{T}_{2}$ (Deg C) & $\mathrm{T}_{3}($ Deg C) \\
\hline $60 \mathrm{~W}$ & 125.5 & 126.7 & 125.3 \\
\hline $70 \mathrm{~W}$ & 150.9 & 151.8 & 150.2 \\
\hline $80 \mathrm{~W}$ & 174.9 & 173.2 & 205.9 \\
\hline $90 \mathrm{~W}$ & 206.1 & 206.5 & \\
\hline
\end{tabular}

\begin{tabular}{|c|c|c|c|c|c|c|c|c|c|}
\hline $\begin{array}{c}\text { Heat Generated } \\
\text { (Watt) }\end{array}$ & $\begin{array}{c}\mathrm{T}_{1} \\
(\text { Deg C) }\end{array}$ & $\begin{array}{c}\mathrm{T}_{2} \\
(\text { Deg C) }\end{array}$ & $\begin{array}{c}\mathrm{T}_{3} \\
(\text { Deg C) }\end{array}$ & $\mathrm{T}_{4}$ & $\begin{array}{c}\mathrm{T}_{5} \\
\text { (Deg C) }\end{array}$ & $\begin{array}{c}\mathrm{T}_{6} \\
(\text { Deg C) }\end{array}$ & $\begin{array}{c}\mathrm{T}_{7} \\
\text { (Deg C) }\end{array}$ & $\begin{array}{c}\mathrm{T}_{8} \\
\text { (Deg C) }\end{array}$ & $\begin{array}{c}\mathrm{T}_{9} \\
(\text { Deg C) }\end{array}$ \\
\hline $60 \mathrm{~W}$ (Foam 1) & 75.1 & 78 & 77 & 64.1 & 63.3 & 58.1 & 57.9 & 49.2 & 48.9 \\
\hline 60 W(Foam 2) & 78.1 & 79.1 & 77.9 & 58.5 & 58 & 55.1 & 54.8 & 47.5 & 44.4 \\
\hline 60 W(Foam 3) & 74.1 & 75.8 & 74 & 49.1 & 48 & 46.7 & 45 & 41.3 & 42.9 \\
\hline
\end{tabular}

\begin{tabular}{|c|c|c|c|c|c|c|c|c|c|}
\hline $\begin{array}{c}\text { Heat } \\
\text { (Watt) }\end{array}$ & $\begin{array}{c}\mathrm{T}_{1} \\
\text { (Deg C) }\end{array}$ & $\begin{array}{c}\mathrm{T}_{2} \\
(\text { Deg C) }\end{array}$ & $\begin{array}{c}\mathrm{T}_{3} \\
\text { (Deg C) }\end{array}$ & $\begin{array}{c}\mathrm{T}_{4} \\
(\text { Deg C) }\end{array}$ & $\begin{array}{c}\mathrm{T}_{5} \\
\text { (Deg C) }\end{array}$ & $\begin{array}{c}\mathrm{T}_{6} \\
\text { (Deg C) }\end{array}$ & $\begin{array}{c}\mathrm{T}_{7} \\
\text { (Deg C) }\end{array}$ & $\begin{array}{c}\mathrm{T}_{8} \\
\text { (Deg C) }\end{array}$ & $\begin{array}{c}\mathrm{T}_{9} \\
\text { (Deg C) }\end{array}$ \\
\hline $70 \mathrm{~W}$ (Foam 1) & 95.4 & 98.5 & 97.1 & 77 & 77.2 & 74.4 & 73.6 & 69.6 & 70.3 \\
\hline 70 W(Foam 2) & 92.3 & 94.5 & 93.2 & 62.1 & 60.5 & 59.3 & 59.7 & 55.5 & 56.7 \\
\hline 70 W(Foam 3) & 99.2 & 99.8 & 98 & 61.2 & 61 & 57 & 57.8 & 54.2 & 53.5 \\
\hline
\end{tabular}

\begin{tabular}{|c|c|c|c|c|c|c|c|c|c|}
\hline $\begin{array}{c}\text { HeatGenerated } \\
\text { (Watt) }\end{array}$ & $\begin{array}{c}\mathrm{T}_{1} \\
(\text { Deg C) }\end{array}$ & $\begin{array}{c}\mathrm{T}_{2} \\
(\text { Deg C) }\end{array}$ & $\begin{array}{c}\mathrm{T}_{3} \\
(\text { Deg C) }\end{array}$ & $\begin{array}{c}\mathrm{T}_{4} \\
(\text { Deg C) }\end{array}$ & $\begin{array}{c}\mathrm{T}_{5} \\
(\text { Deg C) }\end{array}$ & $\begin{array}{c}\mathrm{T}_{6} \\
\text { (Deg C) }\end{array}$ & $\begin{array}{c}\mathrm{T}_{7} \\
\text { (Deg C) }\end{array}$ & $\begin{array}{c}\mathrm{T}_{8} \\
\text { (Deg C) }\end{array}$ & $\begin{array}{c}\mathrm{T}_{9} \\
(\text { Deg C) }\end{array}$ \\
\hline $80 \mathrm{~W}$ (Foam 1) & 108.8 & 108.9 & 107 & 83 & 83.6 & 81 & 81.2 & 80.6 & 79.3 \\
\hline 80 W(Foam 2) & 100.5 & 103.7 & 102.4 & 74.6 & 74.8 & 73 & 72.5 & 70.3 & 69.8 \\
\hline 80 W(Foam 3) & 106 & 107 & 105.5 & 60.4 & 59.9 & 58.2 & 58.5 & 56 & 55.8 \\
\hline
\end{tabular}

\begin{tabular}{|c|c|c|c|c|c|c|c|c|c|}
\hline $\begin{array}{c}\text { Heat generated } \\
\text { (Watt) }\end{array}$ & $\begin{array}{c}\mathrm{T}_{1} \\
\text { (Deg C) }\end{array}$ & $\begin{array}{c}\mathrm{T}_{2} \\
(\text { Deg C) }\end{array}$ & $\begin{array}{c}\mathrm{T}_{3} \\
\text { (Deg C) }\end{array}$ & $\begin{array}{c}\mathrm{T}_{4} \\
(\text { Deg C) }\end{array}$ & $\begin{array}{c}\mathrm{T}_{5} \\
(\text { Deg C) }\end{array}$ & $\begin{array}{c}\mathrm{T}_{6} \\
\text { (Deg C) }\end{array}$ & $\begin{array}{c}\mathrm{T}_{7} \\
\text { (Deg C) }\end{array}$ & $\begin{array}{c}\mathrm{T}_{8} \\
\text { (Deg C) }\end{array}$ & $\begin{array}{c}\mathrm{T}_{9} \\
(\text { Deg C) }\end{array}$ \\
\hline 90W(Foam 1) & 137.5 & 138.23 & 136.3 & 99.9 & 99.6 & 95 & 86.5 & 94.3 & 86 \\
\hline 90W(Foam 2) & 117.4 & 120.9 & 118.5 & 79.1 & 78.9 & 77.1 & 78.5 & 77.5 & 78.1 \\
\hline 90W(Foam 3) & 116.8 & 117.8 & 115.7 & 57.1 & 56 & 54.3 & 56.6 & 55.1 & 57 \\
\hline
\end{tabular}




\section{Results and discussions}

The following graph show the reading taken for different flux ranging between 2 to $2.5 \mathrm{~W} / \mathrm{cm}^{2}$.the fig 4 Show the temperature of the copper plate with and without regular aluminum open cell cellular structure sample attached to it and heated from below. The graph show that as the regular open cell cellular structure attached to the copper plate the temperature of the copper plate is considerably reduced.

The graph between the average heat transfer coefficient and heat generated (Fig.5) has been drawn at steady state. It is clearly shown in the graph that the heat transfer coefficient has been considerably increased as the regular aluminum open cell cellular structure material is attached to the plate.

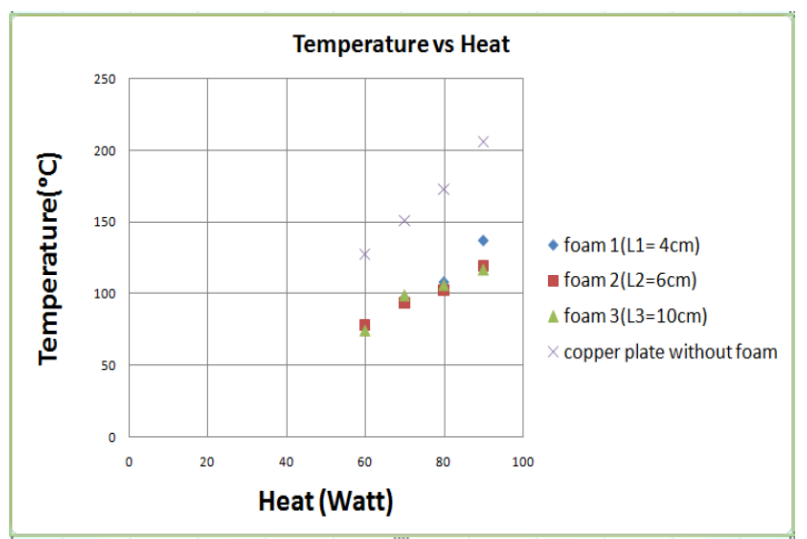

Figure 4: Temperature of copper plate with or without regular aluminum open cell cellular structure vs heat generated

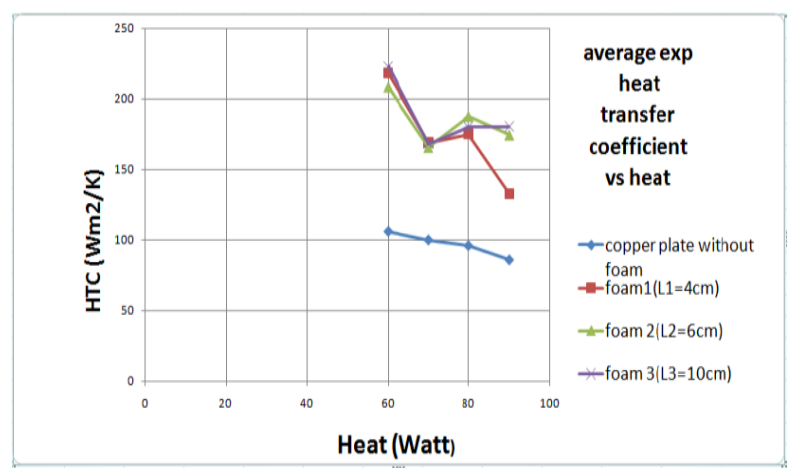

Figure 5: Average heat transfer coefficient vs heat generated

Based on the temperature reading the fig $(6,7,8)$ between Nusselt number and Rayleigh number has been drawn for different samples of aluminum open cell regular structure. The height of the aluminum open cell regular structure is taken as the characteristic length to calculate the Nusselt number and Rayleigh number. The thermo physical properties of air are considered at the mean temperature of the copper plate and ambient air.As the aluminum foam has very high surface to volume ratio. It is clearly shown in the graph that the heat transfer coefficient has been considerably increased as the regular aluminum open cell cellular structure material is attached to the plate. Since the Average heat transfer coefficient is calculated by balancing of energy equation considering the area of copper plate as the base area it is clearly shown by experimentation that the heat transfer is considerably increased. The increase in heat transfer coefficient is almost $100 \%$ for the first sample and decreases as the heat flux is increased. As per the experimentation it is seen that the same trends has been followed by the other samples too.

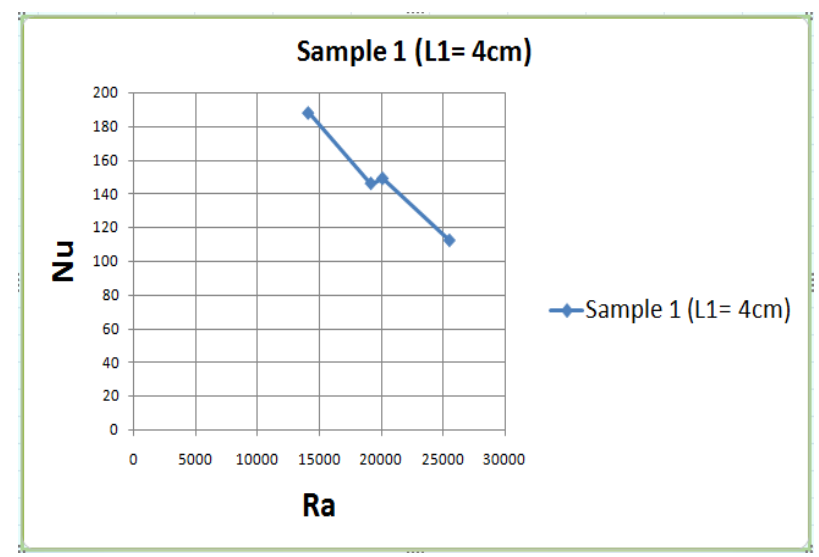

Figure 6: Nusselt number vs Rayleigh number for Sample1

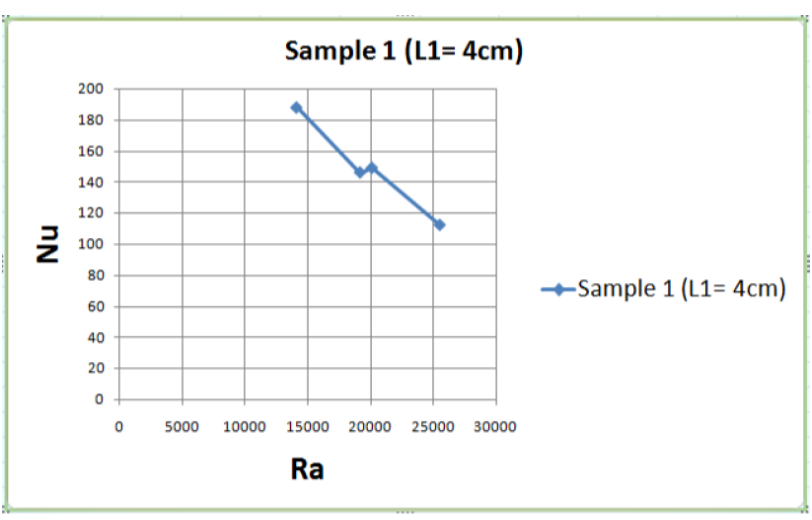

Figure 7: Nusselt number vs Rayleigh number for Sample2

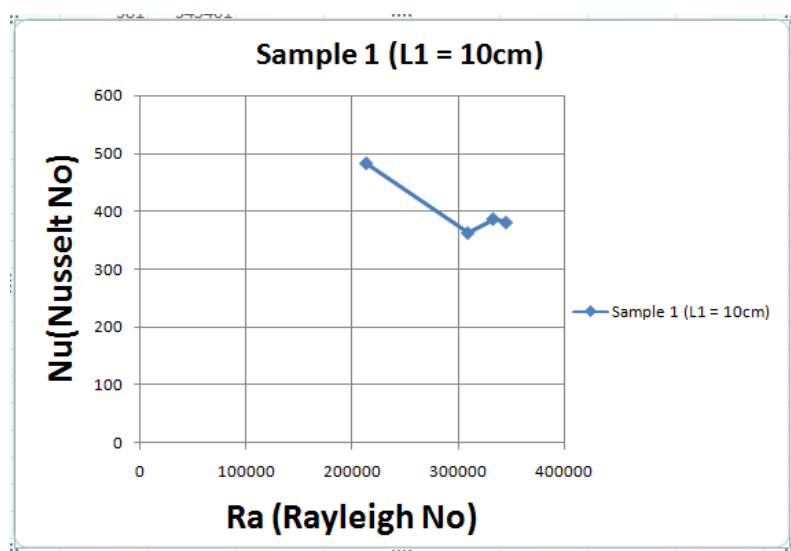

Figure8: Nusselt number vs. Rayleigh number for Sample3 
The fig 9. Show the graph between Nusselt number and Rayleigh number. It is shown in the figure that as the Rayleigh number is increased (by increasing the height of the sample pieces) the Nusselt number also increases. But Nusselt number increases at the higher rate as the height of the regular aluminum open cell cellular structure increases for the 60 Watt heat generation. But the height of the aluminum foam increased there is point came when no increase in heat transfer takes place since the end point of the foam will reach the temperature of the ambient temperature. So heat transfer increase upto certain height only.

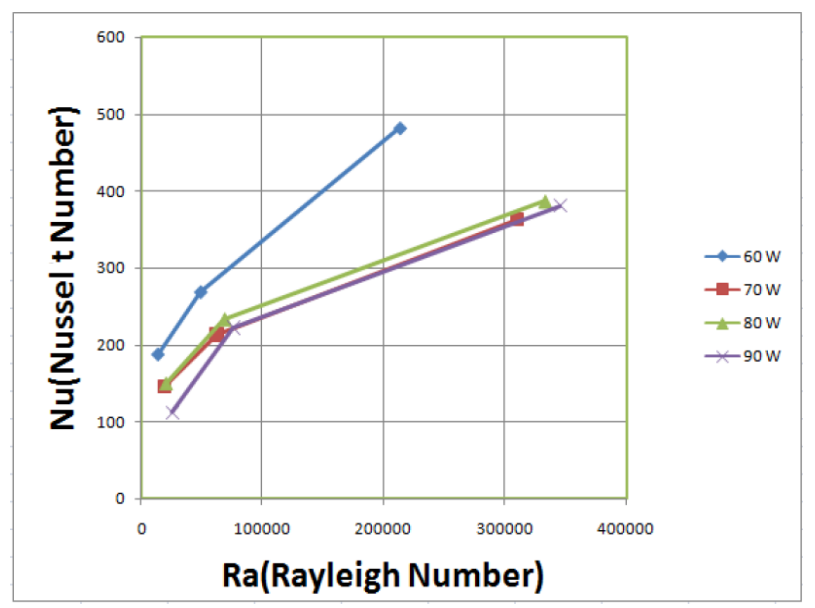

Fig9. Nusselt number vs Rayleigh number for different heat flux

\section{Conclusions}

The Natural convective heat transfer through Regular open cell Aluminum cellular structure is study experimentally for samples of different height and reading are compared with the base case when no samples is attached to the cooper plate only it is heated from below.

a) It is figure out that temperature of the copper plate is considerably reduce if the Regular open cell Aluminum cellular structure are attached to the copper plate. Showing there is a increase in heat transfer coefficient for the same area of base plate (cooper plate). So the Regular open cell Aluminum cellular structure can dissipate more amount of heat for the same temperature difference and same base area of the base plate (copper plate) compared to the base case when copper plate is heated from below without cellular structure attached to it.

b) The heat transfer coefficient is considerably increased as the regular aluminum open cell cellular structure is attached to the copper plate. c) The graph between the Nusselt number and Rayleigh number shows that the Nusselt number decreases as the Rayleigh number increases (by increasing heat flux) for the sample $1(\mathrm{~L} 1=4 \mathrm{~cm})$.

d) The Nusselt number increases as the Rayleigh number increases by increasing the characteristic length (Height of the samples).it is certain that as the height of the sample increases the air will reach the temperature of upper most part of open cell foam by exchanging maximum amount of heat.

\section{Acknowledgement}

Rahul Singh Poonia gratefully acknowledges the support from Prof.Mandar M. Lele of Mechanical Engg department, MIT, Pune and Mechanical staff for its technical support.

\section{Nomenclature}

A Area of copper plate base

L height of the sample pieces

$\mathrm{Nu} \quad$ Nusselt number

Q Heat input to heater

$\mathrm{P} \quad$ heat generated

$p_{\text {rad }} \quad$ Heat radiated

$p_{\text {conv }} \quad$ Heat convected

$\mathrm{Ra} \quad$ Rayleigh number

TaBase temperature

TambAmbient Temperature ${ }^{\circ} \mathrm{C}$

TwallCopper plate temperature

$T_{b 1}, T_{b 2}, T_{b 3}$ Average temperature of cellular structure $A_{1}, A_{2}, A_{3} \quad$ Area of different side of cellular structure

Greek symbols

$\epsilon_{a}$ Emissivity of the aluminum

\section{References}

M.S. Phanikumar, R.L. Mahajan (2002).Non-Darcy natural convection in high porosity metal foams. International Journal of Heat and Mass Transfer 45 (3781-3793).

G. Hetsroni, M. Gurevich, R. Rozenblit. (2008) Natural convection in metal foam strips with internal heat generation, Experimental Thermal and Fluid Science 32 (1740-1747).

Sven De Schampheleire, Peter De Jaeger, Kathleen De Kerpel, Bernd Ameel, Henk Huisseune, Michel De Paepe (2014) Experimental study of free convection in open-cell aluminium foam, Procedia Materials Science 4 (340 - 345).

Qu, T. Wang, W. Tao, T. Lu, (2012) Experimental study of air natural convection on metallic foam-sintered plate, Int Jounal Heat Fluid Flow, vol. 38 (126-132)

Principle of Heat transfer in porous media by Massod Kaviany 